\title{
Genetic analysis of morphological and functional traits in Campolina horses using Bayesian multi-trait model
}

\author{
Fernando de Oliveira Bussiman ${ }^{\mathrm{a}, *}$, Bruno da Costa Perez ${ }^{\mathrm{a}}$, Ricardo Vieira Ventura ${ }^{\mathrm{b}, \mathrm{c}, \mathrm{d}}$, \\ Fabyano Fonseca e Silva ${ }^{\mathrm{e}}$, Maria Gabriela Campolina Diniz Peixoto ${ }^{\mathrm{f}}$, Rafael Guimarães Vizoná ${ }^{\mathrm{b}}$, \\ Elisângela Chicaroni Mattos ${ }^{g}$, José Bento Sterman Ferraz ${ }^{g}$, Joanir Pereira Eler ${ }^{g}$, \\ Rogério Abdallah Curi ${ }^{\mathrm{h}}$, Júlio Cesar de Carvalho Balieiro ${ }^{\mathrm{b}}$
}

a Department of Animal Sciences, College of Animals Science and Food Engineering, University of São Paulo (FZEA/USP), Pirassununga, São Paulo, Brazil

b Department of Animal Nutrition and Production, College of Veterinary Medicine and Animal Science, University of São Paulo (FMVZ/USP), Pirassununga, São Paulo, Brazil

${ }^{\mathrm{c}}$ Beef Improvement Opportunities (BIO), Elora, Ontario, Canada

d Department of Animal and Poultry Science, University of Guelph, Guelph, Ontario, Canada

e Department of Animal Science, Federal University of Viçosa (DZO/UFV), Viçosa, Minas Gerais, Brazil

${ }^{\mathrm{f}}$ National Centre of Research on Dairy Cattle, Brazilian Agricultural Research Corporation(CNPGL/EMBRAPA), Juiz de Fora, Minas Gerais, Brazil

${ }^{g}$ Group of Genetic Improvement and Biotechnology, Department of Veterinary Science, College of Animal Science and Food Engineering, University of São Paulo (GMABFZEA/USP), Pirassununga, São Paulo, Brazil

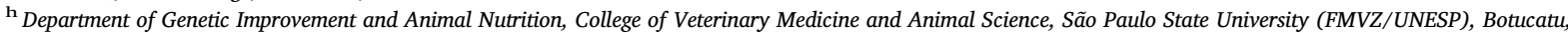
São Paulo, Brazil

\section{A R T I C L E I N F O}

\section{Keywords:}

Gaited horse

Quantitative genetics

Genetic correlations

Multi-trait models

Bayesian inference

\begin{abstract}
A B S T R A C T
In general, is said that functional traits have a positive genetic correlation with conformation in horses but, this hypothesis has never been investigated in the Brazilian Campolina breed. We aimed to estimate genetic parameters (heritabilities and genetic correlations) for these traits based on genealogical records from 107,951 animals, in which 43,159 were phenotyped. A total of 16 morphological traits (MT); one gaits score (GtS) and two traits related to conformation harmony $(\mathrm{CH})$, were simultaneously analysed under a Bayesian multi-trait model framework. Genetic trends were estimated over the years of birth for animals born between 1951 and 2016. MT were all genetically positively associated (from 0.05 to 0.98 ). $\mathrm{CH}$ traits presented positive and negative genetic correlations, but all favourable to the selection goals. GtS was negatively associated with all MT, except for Chest Width (0.08). $\mathrm{CH}$ and GtS presented lower positive genetic correlation $(0.10$ and 0.01 , for the ratio between Height at Withers and Height at Back, and ratio of Back-Loins Length over Body Length, respectively). Observed results indicated the existence of sufficient additive genetic variance (heritability estimates ranged from 0.07 to 0.43 ) for the studied traits, benefiting the implementation of a breeding program, if the desired is to select animals for morphology or gaits. All genetic trends were favorable despite of the phenotypic selection in the Campolina breed. These trends presented low regression coefficients, but the increase on average predicted breeding values for the investigated period was $137.9 \%$.
\end{abstract}

\section{Introduction}

The Brazilian Campolina gaited horse has its origins in the Iberian Peninsula horse population. The first evidence of Campolina horses was reported in Minas Gerais State (MG) around the year 1870 by using European stallions (Anglo-Norman, Clydesdale, Holsteiner, Percheron and Thoroughbred) in a crossbred stud of mares (Andalusian, Lusitano and Berber) (Procópio et al., 2003). The breeders' association
(Campolina Horse Breeders Association - ABCCCampolina, http:// www.campolina.org.br/portal/) was founded in 1951, and currently, Campolina is the sixth larger horse population in Brazil (Vieira et al., 2015). Historically, the social-economic development at MG was linked to horse breeding (Rezende and Moura, 2004), which shows the relevance of this breed nationwide. Recently, Campolina animals have been exported to Mexico, Venezuela, USA and Germany, achieving more global presence. The Campolina population has never been under

\footnotetext{
* Corresponding author.

E-mail address: fernando.bussiman@usp.br (F.d.O. Bussiman).
} 
an official breeding program, thus selection is mainly phenotypic, based on results of horse shows and gaits competitions. Once genetic association between gaits and morphological traits was never studied in this breed, genetic parameters for morphological and functional traits, as well as the genetic correlations between gaits and morphology should be investigated.

Single trait models are used to access the estimated breeding values (EBV) in many livestock breeding programs. In this context, the EBVs are combined according to their economic value in the breeding goal (Lassen et al., 2007). A way to increase the EBV accuracy by taking into account possible correlations between all considered traits is to use multi-trait models, which allow combining direct and indirect information for breeding goal purposes (Thompson and Meyer, 1986; van der Werf et al., 1992). However, under a higher number of traits, these models are very complex to be fitted through maximum likelihoodbased methods. In this context, Bayesian inference stands out as a suitable and efficient statistical tool. According to Sorensen \& Gianola (2002), one relevant advantage of Bayesian inference is to accommodate high dimensional multi-trait models by using Markov chain- Monte Carlo (MCMC) sampling methods.

Following this orientation, we aimed to estimate genetic parameters (heritabilities and genetic correlations) for morphological and functional traits in Brazilian Campolina horses under a Bayesian multi-trait model approach to turn suitable the selection for gaits on this breed. Additionally, genetic trends were also estimated over the years of birth since the foundation of the breeders association.

\section{Material and methods}

\subsection{Available data}

Datasets considered for the present study were provided by the ABCCCampolina and contained 43,159 records for 16 morphological and 1 functional trait. Genealogical data was composed by 107,951 animals born between 1960 and 2014, constituting a total of 14 generations. The pedigree contained 4253 sires and 26,760 dams, with an average number of 21.54 and 3.42, respectively. Approximately $45 \%$ of all pedigreed animals presented some level of inbreeding. The mean inbreeding coefficient was $5.64 \%$ for the inbreds and $2.45 \%$ when considering the complete population (a more detailed description of this population can be found in Bussiman et al., 2018).

The recorded phenotypes were: Height at Withers (HW); Height at Back (HB); Height at Croup (HC); Height at Chest (HCh); Leg Length (LL); Head Width (HWi); Chest Width (CW); Buttock Width (BW); Head Length (HL); Neck Length (NL); Back-Loins Length (BLL); Croup Length (CL); Shoulder Length (SL); Body Length (BL); Heart Girth (HG) and Cannon Girth (CG), for the morphological traits (MT) (a systematic representation of all measurement is presented in Supplementary Material - Fig. 1). The average age of animals at measurement was $36.80 \pm 4.66$ months. Minimum and maximum ages at phenotyping were 22.27 and 52.02 months of age, respectively, for the younger and the older horses. Descriptive statistics for these phenotypic records for males and females are presented in Table 1.

\subsection{Data editing}

In order to improve prediction accuracy and reduce bias in the proposed analyzes, consistency checks were performed in the datasets. All missing data, outliers (values 3.5 standard deviations above/below the phenotypic mean), contemporary groups with less than five observations and/or which animals were progeny of less than three sires were eliminated from the datasets prior to analysis. Levels for the technician effect with less than 15 observations were eliminated from the original datasets.

\subsection{Functional traits}

Campolina animals are categorized according to the gaits pattern, differing in lateral or diagonal proportion of support. The gaits with major proportion of lateral support is named "Marcha Picada", and the one displaying major diagonal support is referred as "Marcha Batida". At the moment of registration, animals are visually evaluated (before, and after being ridden) and scores as designated to each animal. Gaits scores considered are: Dissociation (Di); Style (S); Regularity (R); Development (De) and Comfort (C). According to breed standards of the Campolina Horse Breeders Association (ABCCCampolina):

Di - represent the coordinated movement of anterior and posterior limbs, with support and suspension of limb-pairs of diagonal or lateral form, causing the triple-hoof-support, which guarantee that horse don't lose contact with the ground. This is ranged from 0 (animal without dissociation - nearly to trot) to 40 (animals with maximum of dissociation, providing clearly visualization of triple support);

$S$ - represent the combination of natural posture with balance, harmony, elegance and energy of movements, which variate between 0 (for animals with no beauty of movements) and 40 (animals that have a very good balance of elevation of limbs and are elegant in movement);

$\mathrm{R}$ - is the maintenance of the same type gaits during the movement, conserving itself defined ("batida" or "picada" gaits) and stable, with rhythm and cadence, which is ranged from 0 (animals that change the gaits or loosen rhythm during the movement) to 30 (animals that can persist with the same pattern of movement for long time periods);

De - represent the capability of the horse to travel the longest possible distance with the fewest steps, and the range of this score is from 0 (many steps) to 30 (few steps).

$\mathrm{C}$ - is the aspect of quality from movements of horse without oscillations, providing no vertical, lateral or frontal impacts to the rider. It is ranged from 0 (animals with many impacts, making the ridden uncomfortable) to 60 (extremely comfortable animals, with no impacts to rider);

The total gaits score (GtS - ranged between 100 and 200) was evaluated as the sum of the 5 functional score traits mentioned, as follows:

$G t S=D i+S+R+D e+C$,

As gaits traits were recently introduced in the registering process by the ABCCCampolina, there were 4374 records available to perform the analyses. All phenotyped animals for GtS also had morphological measurements.

\subsection{Conformation harmony traits}

Considering that traditional morphological measurements only express a one-dimensional aspect of the horse conformation, here we propose two new phenotypes, built by the combination of two traditional traits in order to investigate its usage as selection criteria in the Campolina breed. The ratio between HW and HB (HWHB), interpreted directly as the difference in height at withers and at croup $(H W H B=H W / H B)$. For this trait, the values close to 1 are desirable. The ratio between BLL and BL $(B L L B L=B L L / B L)$ which can be interpreted as the proportion of the back-loin region of a horse over the body length. In this case, longer values for BL and shorter values for BLL are desirable Table 2.

\subsection{Estimation of variance components}

A multi-trait model was proposed to perform the genetic analyzes in 
Table 1

Descriptive statistics for the morphological traits in Campolina horse breed used in present study, grouped according to sex.

\begin{tabular}{|c|c|c|c|c|c|c|c|c|c|c|}
\hline \multirow[t]{2}{*}{ Variable } & \multicolumn{5}{|l|}{ Males } & \multicolumn{5}{|l|}{ Females } \\
\hline & $N_{m}$ & $\bar{X}$ & $\mathrm{SD}^{1}$ & Min & $\operatorname{Max}$ & $N_{f}$ & $\bar{X}$ & $\mathrm{SD}^{1}$ & Min & Max \\
\hline $\mathrm{HW}(\mathrm{cm})$ & 7,477 & 159.01 & 4.43 & 138.00 & 171.00 & 35,682 & 152.26 & 5.37 & 136.00 & 171.00 \\
\hline $\mathrm{HB}(\mathrm{cm})$ & 7,477 & 151.11 & 4.46 & 131.00 & 168.00 & 35,682 & 145.29 & 5.23 & 129.00 & 170.00 \\
\hline $\mathrm{HC}(\mathrm{cm})$ & 7,477 & 158.21 & 4.41 & 133.00 & 172.00 & 35,682 & 152.31 & 5.26 & 135.00 & 178.00 \\
\hline $\mathrm{HCh}(\mathrm{cm})$ & 7,477 & 64.75 & 3.03 & 52.00 & 77.00 & 35,682 & 64.55 & 3.06 & 52.00 & 77.00 \\
\hline $\mathrm{LL}(\mathrm{cm})$ & 7,477 & 94.26 & 3.99 & 77.00 & 108.00 & 35,682 & 87.71 & 4.69 & 70.00 & 107.00 \\
\hline $\mathrm{HWi}(\mathrm{cm})$ & 7,477 & 21.45 & 1.09 & 17.00 & 25.00 & 35,682 & 20.79 & 1.01 & 17.00 & 25.00 \\
\hline $\mathrm{CW}(\mathrm{cm})$ & 7,477 & 41.19 & 2.82 & 29.00 & 49.00 & 35,682 & 38.31 & 2.73 & 28.00 & 49.00 \\
\hline $\mathrm{BW}(\mathrm{cm})$ & 7,477 & 52.53 & 2.66 & 40.00 & 63.00 & 35,682 & 51.74 & 2.88 & 40.00 & 63.00 \\
\hline HL $(\mathrm{cm})$ & 7,477 & 62.29 & 2.67 & 50.00 & 72.00 & 35,682 & 60.11 & 2.73 & 48.00 & 72.00 \\
\hline $\mathrm{NL}(\mathrm{cm})$ & 7,477 & 65.65 & 3.72 & 50.00 & 77.00 & 35,682 & 62.48 & 3.63 & 49.00 & 77.00 \\
\hline BLL $(\mathrm{cm})$ & 7,477 & 59.30 & 6.27 & 41.00 & 80.00 & 35,682 & 60.36 & 6.06 & 40.00 & 80.00 \\
\hline $\mathrm{CL}(\mathrm{cm})$ & 7,477 & 52.36 & 4.19 & 38.00 & 64.00 & 35,682 & 50.76 & 3.71 & 38.00 & 64.00 \\
\hline $\mathrm{SL}(\mathrm{cm})$ & 7,477 & 57.83 & 3.95 & 42.00 & 71.00 & 35,682 & 56.05 & 3.93 & 42.00 & 71.00 \\
\hline $\mathrm{BL}(\mathrm{cm})$ & 7,477 & 161.03 & 5.81 & 132.00 & 182.00 & 35,682 & 155.15 & 6.51 & 130.00 & 186.00 \\
\hline $\mathrm{HG}(\mathrm{cm})$ & 7,477 & 182.87 & 7.13 & 150.00 & 220.00 & 35,682 & 181.64 & 7.84 & 142.00 & 220.00 \\
\hline $\mathrm{CG}(\mathrm{cm})$ & 7,477 & 19.58 & 1.20 & 10.00 & 28.00 & 35,682 & 18.80 & 1.05 & 10.00 & 30.00 \\
\hline
\end{tabular}

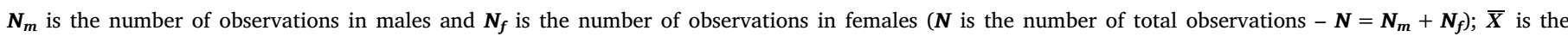
phenotypic mean; Min is the minimum value of the observed data and Max is the maximum value of the observations.

$1 \mathrm{SD}=$ standard deviation.

this study. All morphological/conformation harmony (2) traits and the gaits scores (3) were evaluated based on the following effects:

$Y_{i j k l m}=C G_{i}+\operatorname{Stud}_{j}+Y R_{k}+\operatorname{Sex}_{l}+\beta_{1} A g e+\beta_{2} A g e^{2}+u_{m}+e_{i j k l m}$,

$Y_{i j k m n}=C G_{i}+\operatorname{Stud}_{j}+Y R_{k}+\beta_{1} A g e+\beta_{2} A g e^{2}+u_{m}+T e c_{n}+e_{i j k m n}$,

where $Y$. is the phenotypic information; $C G_{i}$ is the systematic effect of contemporary group (year and season of birth); $S t u d_{j}$ is the systematic effect of the stud of birth; $Y R_{k}$ is the systematic effect of year of registry; Sex $x_{l}$ is the systematic effect of sex (male or female); $\beta_{1}$ (linear) and $\beta_{2}$ (quadratic) are the regression coefficients for the covariate Age; $u_{m}$ is the random additive genetic effect of the $m$ th animal; $T e c_{n}$ is the random effect of the $n$th technician (gait evaluator); and $e_{i j k l m n}$ represent the random residual term. In matrix notation, the explicit multitrait model can be expressed as follows:

$\mathbf{y}=\mathbf{X} \beta+\mathbf{Z u}+\mathbf{W t}+\mathbf{e}$,

where:y is the vector of phenotypic observations for all considered traits, assumed as $\mathbf{y} \mid \beta, \mathbf{u}, \mathbf{t}, \mathbf{G}_{0}, \mathbf{T}_{\mathbf{0}}, \mathbf{R}_{0} \sim \mathrm{N}\left(\mathbf{X} \beta+\mathbf{Z u}+\mathbf{W t}, \mathbf{R}_{0} \otimes \mathbf{I}\right) ; \beta$ is the vector of all systematic effects, assumed as $\boldsymbol{\beta} \sim \mathbf{N}\left(0, \Sigma_{\beta} \otimes I\right)$; $\mathbf{u}$ is the vector of random additive genetic effects, assumed as: $\mathbf{a} \mid \mathbf{G}_{0}, \mathbf{A} \sim \mathrm{N}$ $\left(\mathbf{0}, \mathbf{G}_{0} \otimes \mathbf{A}\right)$, being $\mathbf{A}$ the additive relationship matrix among the animals and $\mathbf{G}_{0}$ the additive genetic (co)variance matrix; $\mathbf{t}$ is the random effect of technician (only for gaits score), assumed as $\mathbf{t} \sim \mathrm{N}\left(\mathbf{0}, \sigma_{\mathrm{t}}^{2} \mathbf{I}\right)$. Furthermore, it was assumed that $\mathbf{G}_{0}$ and $\mathbf{R}_{0}$ follows an inverted Wishart distribution, WI $(\mathrm{v}, \mathrm{V})$, with hyperparameters $\mathrm{v}$ and $\mathbf{V}$. For the variance component $\sigma_{\mathrm{t}}^{2}$, it was assumed an inverted chi-squared distribution. The hyperparameter values were chosen to provide non-informative priors, since "previous knowledge" about the parameters to be estimated can be considered "weak" given the lack of studies for the considered traits in this breed; $\mathbf{X}, \mathbf{Z}$ and $\mathbf{W}$ are the incidence matrices of systematic, additive genetic and technician effects, respectively; $\mathbf{e}$ is the residual vector, assumed as $\mathbf{e} \mid \mathbf{R}_{0} \sim \mathrm{N}\left(0, \mathbf{R}_{0} \otimes \mathbf{I}\right)$, where $\mathbf{I}$ and $\mathbf{R}_{\mathbf{0}}$ are, respectively, an identity and residual covariance matrices. The covariance matrices $\left(\mathbf{G}_{0}\right.$ and $\mathbf{R}_{0}$ ) have dimensions $19 \times 19$ because all traits were considered simultaneously in the analysis.

The (co)variance components and genetic parameters were estimated through Gibbs sampler algorithm by using the GIBBSF90 software (Misztal et al., 2002). The posterior marginal distribution samples for heritability of a trait $\mathrm{i}\left(\mathrm{h}_{\mathrm{i}}^{2}\right)$ and genetic correlations between traits $\mathrm{i}$ and $j\left(r_{i j}\right)$ were obtained from the (co)variance components samples generated in each Gibbs sampler iteration (k) as follow: $\mathrm{h}_{\mathrm{i}}^{2(\mathrm{k})}=\sigma_{\mathrm{a}_{\mathrm{i}}}^{2(\mathrm{k})} /\left(\sigma_{\mathrm{a}_{\mathrm{i}}}^{2(\mathrm{k})}+\sigma_{\mathrm{e}_{\mathrm{i}}}^{2(\mathrm{k})}\right) \quad \operatorname{andr}_{\mathrm{ij}}^{(\mathrm{k})}=\sigma_{\mathrm{a}_{\mathrm{ij}}}^{(\mathrm{k})} / \sqrt{\left(\sigma_{\mathrm{a}_{\mathrm{i}}}^{2(\mathrm{k})} \sigma_{\mathrm{a}_{\mathrm{j}}}^{2(\mathrm{k})}\right)}$. For the trait gaits score, the heritability was estimated by: $\mathrm{h}_{\mathrm{i}}^{2(\mathrm{k})}=\sigma_{\mathrm{a}_{\mathrm{i}}}^{2(\mathrm{k})} /\left(\sigma_{\mathrm{ai}^{2}}^{2(\mathrm{k})}+\sigma_{\mathrm{t}_{\mathrm{i}}}^{2(\mathrm{k})}+\sigma_{\mathrm{e}_{\mathrm{i}}}^{2(\mathrm{k})}\right)$. The genetic variances $\left(\sigma_{\mathrm{aj}}^{2}\right)$ and covariances $\left(\sigma_{\mathrm{a}_{\mathrm{ij}}}\right)$ were obtained from $\mathbf{G}_{0}$, and the residual variance $\left(\sigma_{\mathrm{e}_{1}}^{2}\right)$ from $\mathbf{R}_{0}$. A total of 800,000 samples were generated, assuming a burnin period of 200,000 iterations and thinning intervals of 100 . Thus, inference was performed over 6000 samples from the posterior distribution. Convergence evidences were checked by visual inspection of the trace-plots and by applying the $\mathrm{Z}$ criterion of Geweke (Geweke, 1992) and the Raftery-Lewis test (Raftery and Lewis, 1992), implemented in the $\mathrm{R}$ ( $\mathrm{R}$ Core Team, 2016) package "coda" (Plummer et al., 2006). Due to the great number of traits, results for genetic correlations are presented in graphical form (tables are available as Supplementary Material - Table 4). Additionally, the accuracy of the breeding values estimated for GtS obtained on multi- and single-

Table 2

Descriptive statistics for the new traits and the functional trait in Campolina horse breed used in present study, grouped by sex.

\begin{tabular}{|c|c|c|c|c|c|c|c|c|c|c|}
\hline \multirow[t]{2}{*}{ Variable } & \multicolumn{5}{|l|}{ Males } & \multicolumn{5}{|l|}{ Females } \\
\hline & $N_{m}$ & $\bar{X}$ & $\mathrm{SD}^{1}$ & Min & Max & $N_{f}$ & $\bar{X}$ & $\mathrm{SD}^{1}$ & Min & Max \\
\hline HWHB & 7,477 & 1.46 & 0.10 & 1.09 & 2.08 & 35,682 & 1.36 & 0.10 & 0.95 & 1.98 \\
\hline BLLBL & 7,477 & 0.37 & 0.04 & 0.26 & 0.56 & 35,682 & 0.39 & 0.04 & 0.25 & 0.58 \\
\hline GtS & 1,239 & 152.53 & 11.30 & 108.00 & 191.00 & 3,135 & 151.50 & 10.55 & 116.00 & 191.00 \\
\hline
\end{tabular}

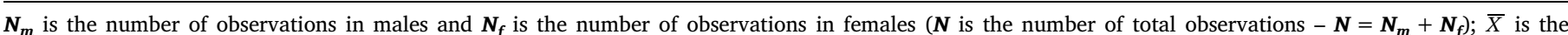

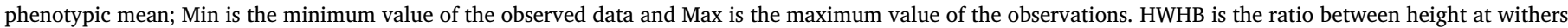
(HW) and height at back (HB); BLLBL is the ratio between back-loins length (BLL) and body length (BL).

1 SD = standard deviation. 
trait analysis was recorded and compared in order to assess the benefits of multi-trait approach to evaluate gaits.

\subsection{Genetic trends}

For the analysis of genetic trends, the year 1951 (foundation of ABCCCampolina) was treated as the beginning of the time period studied. Breeding values of animals born before 1951 were considered equal to 0 as a genetic basis adjustment. The genetic trendlines were calculated by regressing the EBVs for each animal over its respective year of birth for every trait considered. The analysis was implemented in the "lme4" package from R software (Bates et al., 2014). Only animals of which EBV accuracy equal or higher than 0.60 were considered for the genetic trend analysis. The linear regression model was given by:

$\hat{u}_{i j}=\beta_{0}+\beta_{1}$ Year $+e_{i j}$,

where: $\hat{\mathrm{u}}_{\mathrm{ij}}$ is the vector of estimated breeding values of the $i$ th animal in the $j$ th year; $\beta_{0}$ is the constant of regression; $\beta_{1}$ is the regression coefficient of year (representing the vector of birth year for each animal) and $\mathrm{e}_{\mathrm{ij}}$ represent the random residual terms.

\section{Results}

\subsection{Convergence analysis}

The whole set of traits investigated in this study did not present signs of non-convergence. The Z-scores of the Geweke test for the $\sigma_{u}^{2}, \sigma_{e}^{2}$ and $\boldsymbol{h}^{2}$ posterior distribution (Table 3) varied from -3.00 to 3.00 (HB $\sigma_{e}^{2}$ and $\boldsymbol{h}^{2}$, respectively). In most cases the range was between -1.5 and 1.5, these higher Geweke Z-scores suggest that a longer burn-in period would help attaining better convergence for some specific components. All parameters have passed in the Raftery-Lewis test (results not shown). The autocorrelation (r-lag50) within chains was moderately low and all parameters passed the Heidelberger-Welch stationary test (Heidelberger and Welch, 1983). The greatest value of $r$-Lag50 was 0.18 and the smallest -0.02 , when analyzing HG and BW, respectively.

\subsection{Variance components and heritability}

For all traits, estimated parameters presented a Gaussian-like posterior density distribution, except for GtS, which $\sigma_{T E C}^{2}$ had mean $=105.57$ and median $=94.21$. The high-posterior-density intervals (HPDinterval) were relatively narrow for the traits studied (Table 3). Posterior means for the heritability were from moderate to high for the height-related traits (HW, $\mathrm{HB}, \mathrm{HCr}$ and $\mathrm{HCh}$ ), varying from 0.19 ( $\mathrm{HCh}$ ) to 0.43 (HW and $\mathrm{HB}$ ). Length-related traits presented heritability estimates ranging from 0.15 (CL) to 0.34 (BL) and for SL, NL, NLL and HL estimates were: $0.16,0.20,0.23$ and 0.30 , respectively. The width- and girth-related traits had low to moderate heritability, varying from 0.11 (HWi and CG) to 0.21 for BW. Conformation harmony traits presented very low posterior mean estimates for $\sigma_{u}^{2}$, around 0.002 , with heritability of 0.11 and 0.22 , for HWHB and BLLBL, respectively. Due the "strong" effects of technician on GtS, the estimate of heritability was low (0.07). The average increase in accuracy for GtS when considering all phenotyped population was around $+32 \%$ (Supplementary Material - Fig. 2). When considering only the individuals corresponding to the $2 \%$ higher predicted breeding values, the increase in accuracy from single- to multi-trait was $+18.42 \%$ (from 0.38 to 0.45 , respectively). Average relatedness of all phenotyped population is shown in Supplementary Material Fig. 3.

\subsection{Genetic correlations}

Genetic correlations between all studied traits ranged from -0.44 to 0.98 . When considering only negative correlations, values ranged from -0.44 to -0.01 , for $\rho_{u H C h H W H B}$ and $\rho_{u H C B L L B L}$, respectively. For
Table 3

Posterior mean, highest-posterior density interval (HPD Interval), Geweke's (Zscores) and $r$-Lag50 for the estimated genetic parameters for the studied traits: Height at Withers (HW); Height at Back (HB); Height at Croup (HCr); Height at Chest (HCh); Leg Length (LL); Head Width (HWi); Chest Width (CW); Buttock Width (BW); Head Length (HL); Neck Length (NL); Back-Loins Length (BLL); Croup Length (CL); Shoulder Length (SL); Body Length (BL); Heart Girth (HG); Cannon Girth (CG) and Gait Scores (GtS).

\begin{tabular}{|c|c|c|c|c|c|c|c|}
\hline \multirow[t]{2}{*}{ Trait } & & \multirow[t]{2}{*}{ Mean } & \multicolumn{3}{|c|}{ HPD Interval } & \multirow{2}{*}{$\begin{array}{l}\text { Geweke } \\
\text { (Z-score) }\end{array}$} & \multirow[t]{2}{*}{$r-\operatorname{Lag} 50$} \\
\hline & & & $(5 \%$ & | & $95 \%)$ & & \\
\hline \multirow[t]{3}{*}{ HW } & $\sigma_{u}^{2}$ & 7.55 & (7.10 & I & $8.01)$ & -0.82 & 0.01 \\
\hline & $h^{2}$ & 0.43 & $(0.41$ & | & $0.45)$ & -1.06 & 0.01 \\
\hline & $\sigma_{e}^{2}$ & 10.01 & (9.66 & I & 10.34) & 1.40 & 0.00 \\
\hline \multirow[t]{3}{*}{$\mathrm{HB}$} & $\sigma_{u}^{2}$ & 7.22 & $(6.77$ & I & $7.72)$ & 3.48 & 0.06 \\
\hline & $h^{2}$ & 0.41 & $(0.38$ & | & $0.43)$ & 3.00 & 0.07 \\
\hline & $\sigma_{e}^{2}$ & 10.50 & (10.13 & I & 10.85) & -3.47 & 0.05 \\
\hline \multirow[t]{3}{*}{$\mathrm{HC}$} & $\sigma_{u}^{2}$ & 7.37 & $(6.92$ & I & $7.82)$ & -1.58 & 0.03 \\
\hline & $h^{2}$ & 0.43 & $(0.41$ & | & $0.45)$ & -1.71 & 0.03 \\
\hline & $\sigma_{e}^{2}$ & 9.83 & $(9.50$ & i & 10.17) & 1.80 & 0.01 \\
\hline \multirow[t]{3}{*}{$\mathrm{HCh}$} & $\sigma_{u}^{2}$ & 1.55 & (1.38 & I & 1.71) & 1.00 & 0.08 \\
\hline & $h^{2}$ & 0.19 & $(0.18$ & | & $0.21)$ & 1.12 & 0.08 \\
\hline & $\sigma_{e}^{2}$ & 6.41 & $(6.25$ & l & $6.56)$ & -0.90 & 0.04 \\
\hline \multirow[t]{3}{*}{ LL } & $\sigma_{u}^{2}$ & 3.94 & (3.62 & I & 4.27) & 0.33 & 0.06 \\
\hline & $h^{2}$ & 0.27 & $(0.25$ & | & $0.30)$ & 0.35 & 0.06 \\
\hline & $\sigma_{e}^{2}$ & 10.42 & (10.13 & i & 10.68) & -0.36 & 0.03 \\
\hline \multirow[t]{3}{*}{$\mathrm{HWHB}^{1}$} & $\sigma_{u}^{2}$ & 0.00 & $(0.00$ & I & $0.00)$ & 1.48 & 0.15 \\
\hline & $h^{2}$ & 0.11 & $(0.09$ & | & $0.13)$ & 1.38 & 0.15 \\
\hline & $\sigma_{e}^{2}$ & 0.01 & $(0.01$ & i & $0.01)$ & -1.31 & 0.08 \\
\hline \multirow[t]{3}{*}{ HWi } & $\sigma_{u}^{2}$ & 0.10 & $(0.08$ & I & $0.11)$ & 1.33 & 0.16 \\
\hline & $h^{2}$ & 0.11 & $(0.09$ & | & $0.13)$ & 1.43 & 0.16 \\
\hline & $\sigma_{e}^{2}$ & 0.80 & $(0.78$ & I & $0.81)$ & -2.07 & 0.11 \\
\hline \multirow[t]{3}{*}{ CW } & $\sigma_{u}^{2}$ & 1.04 & $(0.92$ & I & 1.15) & 0.74 & 0.04 \\
\hline & $h^{2}$ & 0.16 & $(0.15$ & | & $0.18)$ & 0.71 & 0.04 \\
\hline & $\sigma_{e}^{2}$ & 5.28 & (5.17 & i & $5.40)$ & -0.45 & 0.03 \\
\hline \multirow[t]{3}{*}{ BW } & $\sigma_{u}^{2}$ & 1.40 & $(1.26$ & I & 1.54) & 3.13 & -0.02 \\
\hline & $h^{2}$ & 0.21 & $(0.19$ & | & $0.23)$ & 3.20 & -0.02 \\
\hline & $\sigma_{e}^{2}$ & 5.36 & $(5.23$ & i & 5.49) & -3.37 & -0.02 \\
\hline \multirow[t]{3}{*}{ HL } & $\sigma_{u}^{2}$ & 1.62 & (1.49 & I & 1.73) & 0.89 & 0.01 \\
\hline & $h^{2}$ & 0.30 & $(0.28$ & | & $0.32)$ & 0.97 & 0.01 \\
\hline & $\sigma_{e}^{2}$ & 3.77 & (3.67 & I & 3.88) & -0.89 & 0.01 \\
\hline \multirow[t]{3}{*}{ NL } & $\sigma_{u}^{2}$ & 2.12 & $(1.92$ & I & 2.35) & 1.84 & 0.06 \\
\hline & $h^{2}$ & 0.20 & $(0.18$ & | & $0.22)$ & 1.81 & 0.06 \\
\hline & $\sigma_{e}^{2}$ & 8.28 & (8.09 & i & 8.49) & -1.63 & 0.05 \\
\hline \multirow[t]{3}{*}{ BLL } & $\sigma_{u}^{2}$ & 4.80 & $(4.35$ & | & $5.22)$ & -3.47 & -0.01 \\
\hline & $h^{2}$ & 0.23 & $(0.21$ & | & $0.25)$ & -3.36 & -0.01 \\
\hline & $\sigma_{e}^{2}$ & 16.30 & (15.91 & i & 16.70) & 3.01 & -0.01 \\
\hline BLLBL $^{2}$ & $\sigma_{u}^{2}$ & 0.00 & $(0.00$ & I & $0.00)$ & -1.30 & 0.01 \\
\hline & $h^{2}$ & 0.22 & $(0.20$ & | & $0.24)$ & -1.19 & 0.01 \\
\hline & $\sigma_{e}^{2}$ & 0.00 & $(0.00$ & i & $0.00)$ & 0.53 & 0.01 \\
\hline CL & $\sigma_{u}^{2}$ & 1.64 & (1.47 & | & 1.82) & 1.75 & 0.07 \\
\hline & $h^{2}$ & 0.15 & $(0.14$ & | & $0.17)$ & 1.86 & 0.07 \\
\hline & $\sigma_{e}^{2}$ & 9.26 & (9.07 & I & 9.45) & -2.51 & 0.03 \\
\hline SL & $\sigma_{u}^{2}$ & 1.68 & (1.49 & I & 1.89) & -0.21 & 0.04 \\
\hline & $h^{2}$ & 0.16 & $(0.15$ & | & $0.18)$ & -0.18 & 0.05 \\
\hline & $\sigma_{e}^{2}$ & 8.58 & $(8.38$ & I & $8.77)$ & -0.03 & 0.03 \\
\hline $\mathrm{BL}$ & $\sigma_{u}^{2}$ & 9.72 & $(9.02$ & I & 10.47) & 2.36 & 0.02 \\
\hline & $h^{2}$ & 0.34 & $(0.31$ & | & $0.36)$ & 2.37 & 0.02 \\
\hline & $\sigma_{e}^{2}$ & 19.25 & (18.66 & I & 19.81) & -2.28 & 0.01 \\
\hline HG & $\sigma_{u}^{2}$ & 8.65 & $(7.64$ & I & $9.70)$ & 2.05 & 0.18 \\
\hline & $h^{2}$ & 0.17 & $(0.15$ & | & $0.19)$ & 2.57 & 0.18 \\
\hline & $\sigma_{e}^{2}$ & 42.21 & (41.17 & I & 43.16) & -2.54 & 0.12 \\
\hline CG & $\sigma_{u}^{2}$ & 0.10 & $(0.08$ & I & $0.11)$ & -0.24 & 0.00 \\
\hline & $h^{2}$ & 0.11 & $(0.09$ & | & $0.12)$ & -0.26 & 0.01 \\
\hline & $\sigma_{e}^{2}$ & 0.80 & $(0.78$ & I & $0.82)$ & 0.48 & 0.02 \\
\hline
\end{tabular}

(continued on next page) 
Table 3 (continued)

\begin{tabular}{|c|c|c|c|c|c|c|c|}
\hline \multirow[t]{2}{*}{ Trait } & & \multirow[t]{2}{*}{ Mean } & \multicolumn{3}{|c|}{ HPD Interval } & \multirow{2}{*}{$\begin{array}{l}\text { Geweke } \\
\text { (Z-score) }\end{array}$} & \multirow[t]{2}{*}{$r$-Lag50 } \\
\hline & & & $(5 \%$ & | & $95 \%)$ & & \\
\hline \multirow[t]{4}{*}{ GtS } & $\sigma_{u}^{2}$ & 10.592 & $(4.93$ & | & 14.97) & 1.64 & 0.59 \\
\hline & $h^{2}$ & 0.07 & $(0.03$ & | & $0.11)$ & 1.19 & 0.30 \\
\hline & $\sigma_{e}^{2}$ & 53.94 & $(49.46$ & I & $58.78)$ & -1.93 & 0.37 \\
\hline & $d_{T e c}^{2}$ & 60.00 & (41.00 & 1 & 78.00) & -0.52 & 0.01 \\
\hline
\end{tabular}

1 Real value of the estimated components (HWHB) are (mean, media and HPDinterval): $\sigma_{u}^{2}=0.00098,0.00098$ and $(0.00081 \mid 0.00114) .{ }^{2}$ Real value of the estimated components (BLLBL) are (mean, median and HPDinterval): $\sigma_{u}^{2}=0.00019,0.00019$ and $(0.00017 \mid 0.00021) ; \sigma_{e}^{2}=0.00067,0.00067$ and $(0.00066 \mid 0.00069) . \boldsymbol{d}_{\text {Tec }}^{2}$ is the effect of technician as a proportion of phenotypic variance.

the positive correlations, values ranged from 0.009 to 0.983 , for $\rho_{u H W B L L B L}$ (also for $\rho_{u B L L B L G t S}$ ) and $\rho_{u H W H B}$. Around $80 \%$ of the traits were positively associated (Fig. 1, and Supplementary Material Table 4). The strongest genetic correlations were observed between MT and a set of heights (HW, HB, HCr, HWi), ranging from 0.74 to 0.98 (Supplementary Material - Table 4), for $\rho_{u H C H C h}$ and $\rho_{u H W H B}$. From a total of 361 estimated genetic correlations (18 traits), there were 16 in which the HPDinterval includes the zero value and were not considered significant in this study. They are presented in bold font on Table 4 (Supplementary Material). Around 55\% of genetic correlations which HPDinterval included zero were between GtS and other trait, and all the other genetic correlations for GtS were moderate negative (Fig. 1), ranging from $-0.27\left(\rho_{u G t S H L}\right)$ to $-0.42\left(\rho_{u G t S H G}\right)$. Between morphological traits there were observed only positive genetic correlations, which ranged from 0.24 to 0.91 , for $\rho_{u H W i \text { BLL }}$ and $\rho_{u H W L L}$ (excluding the heights and HDPintervals including zero), respectively.

\subsection{Genetic trends}

The genetic trends were all small (Figs. 2-4), but an increase on phenotypic and breeding values was verified throughout the studied period. All regression coefficients were significantly different from zero (P 0.002) and the adjustment of the genetic basis supported a better fit for the regressions model. The highest values of increase in breeding value per year were found for height traits and BL, varying from 0.02 to $0.03 \mathrm{~cm} /$ year (HG and HW, respectively) (Fig. 2). Lower magnitude trends were obtained for the $\mathrm{CH}$ traits, which were $+0.0002 \mathrm{~cm} /$ year for HWHB and $+0.00001 \mathrm{~cm} /$ year for BLLBL (Fig. 4); for all other traits, the regression coefficient ranged from $0.0071(\mathrm{HCh})$ to 0.0131 (NL). On average, the increase of breeding value between the basis year (1951) and the end of the time period studied (2016) was around $137.9 \%$.

\section{Discussion}

The graphical visualization of the chains showed signs of convergence for all traits. The HPDinterval for variance components and the heritability estimated for GtS were larger than the ones obtained for the same parameters in MT and $\mathrm{CH}$ traits, mostly due to the reduced amount of data available for the analyzes. The Geweke's Z-scores obtained pointed that a greater burn-in period could be a better choice in order to attain more evidence of convergence to some specific parameters. In the case of Z-scores, the method of Geweke attempt both for bias and variance but has the disadvantage of being sensible to the specification of the spectral window (larger thinning intervals tends to benefit the test-result) and still depending on the experience of the statistician (Cowles and Carlin, 1996). The Heidelberger-Welch stationarity test take into account for the transient initial period, apply the test among the chain, thus, could be a good parameter of convergence. In the case of the estimated parameters in the present study under a multi-trait approach, there were a few moderate to high/low Z-scores, which suggests greater thinning and burn-in periods could favor convergence, but all parameters passed through the Heidelberger-Welch test. It is possible that the convergence was affected by the multi-trait structure of the analysis, in such way that the modelling of one trait depends on the magnitude of association with the other analyzed traits.

The benefits of the multi-trait models were investigated since Henderson (1975); some authors reported that this structure of analysis could take more time to converge (Lassen et al., 2007; Villanueva et al., 1993), but the correlations between traits can benefit the accuracy of prediction (Thompson and Meyer, 1986; van der Werf et al., 1992). In this study the estimated parameters in Bayesian multi-trait model were similar to the Bayesian single-model (data not shown), which is a strong

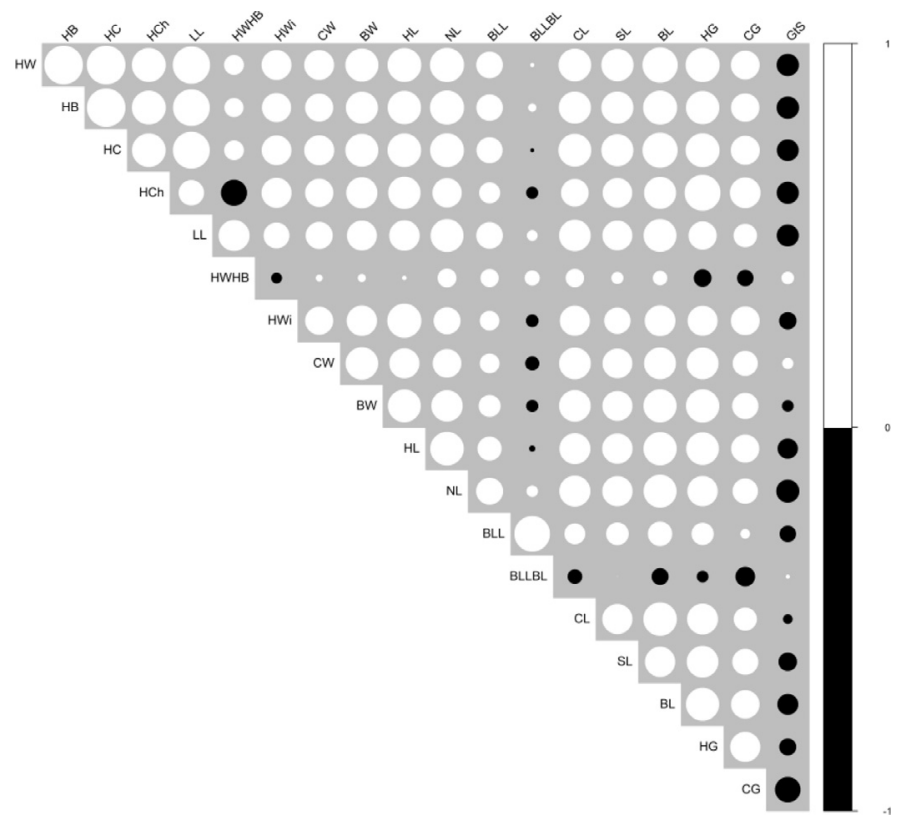

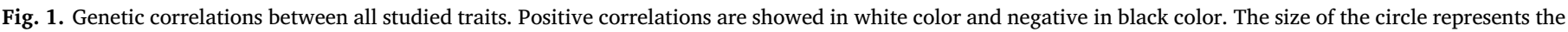
magnitude of the coefficient. 

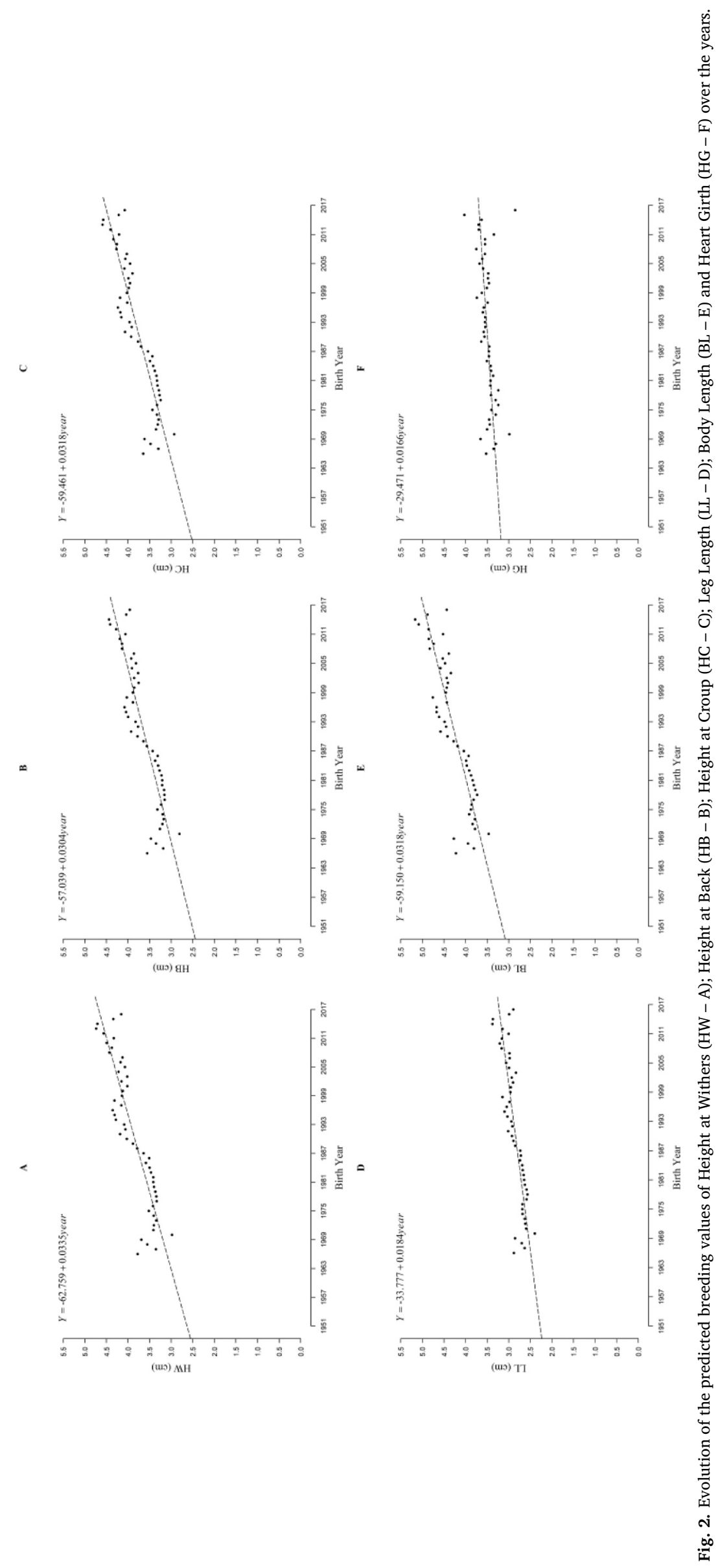


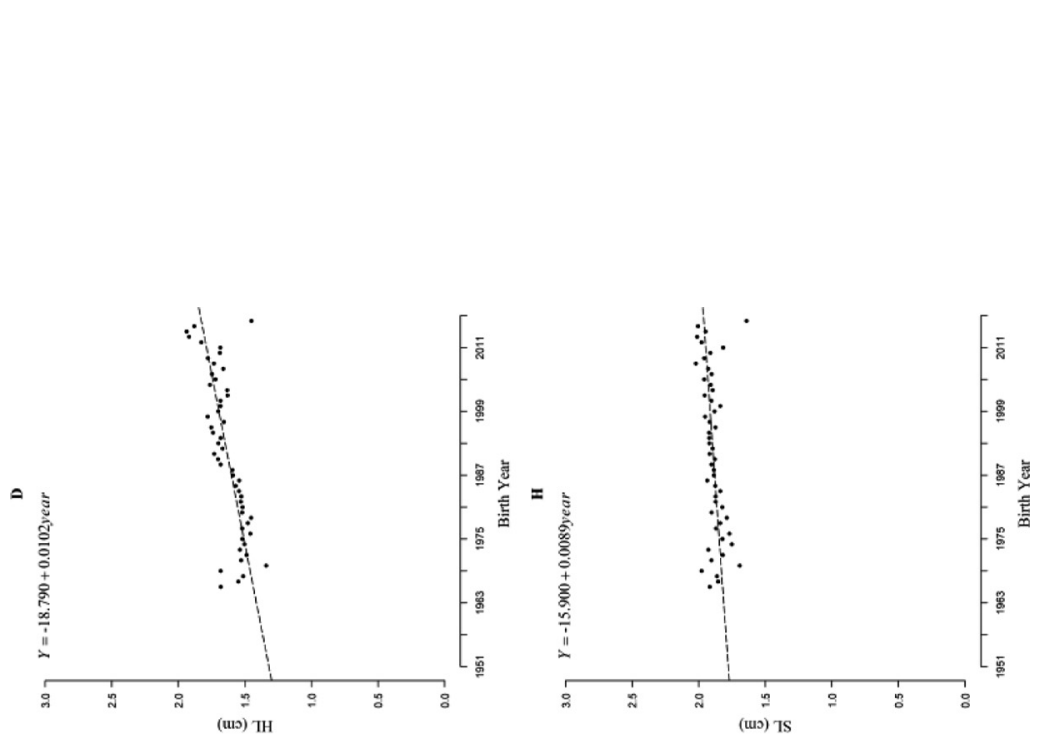

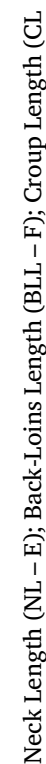
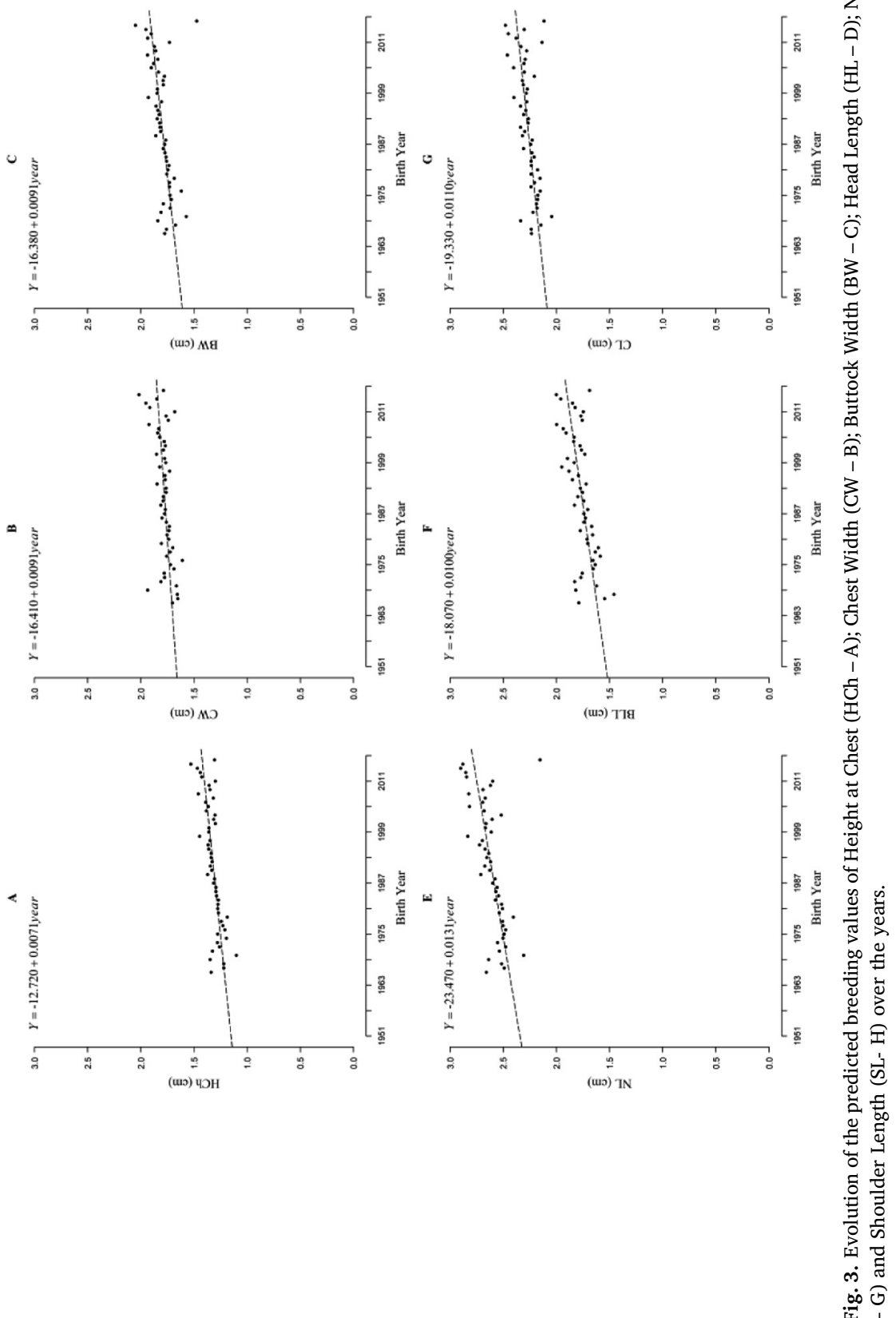

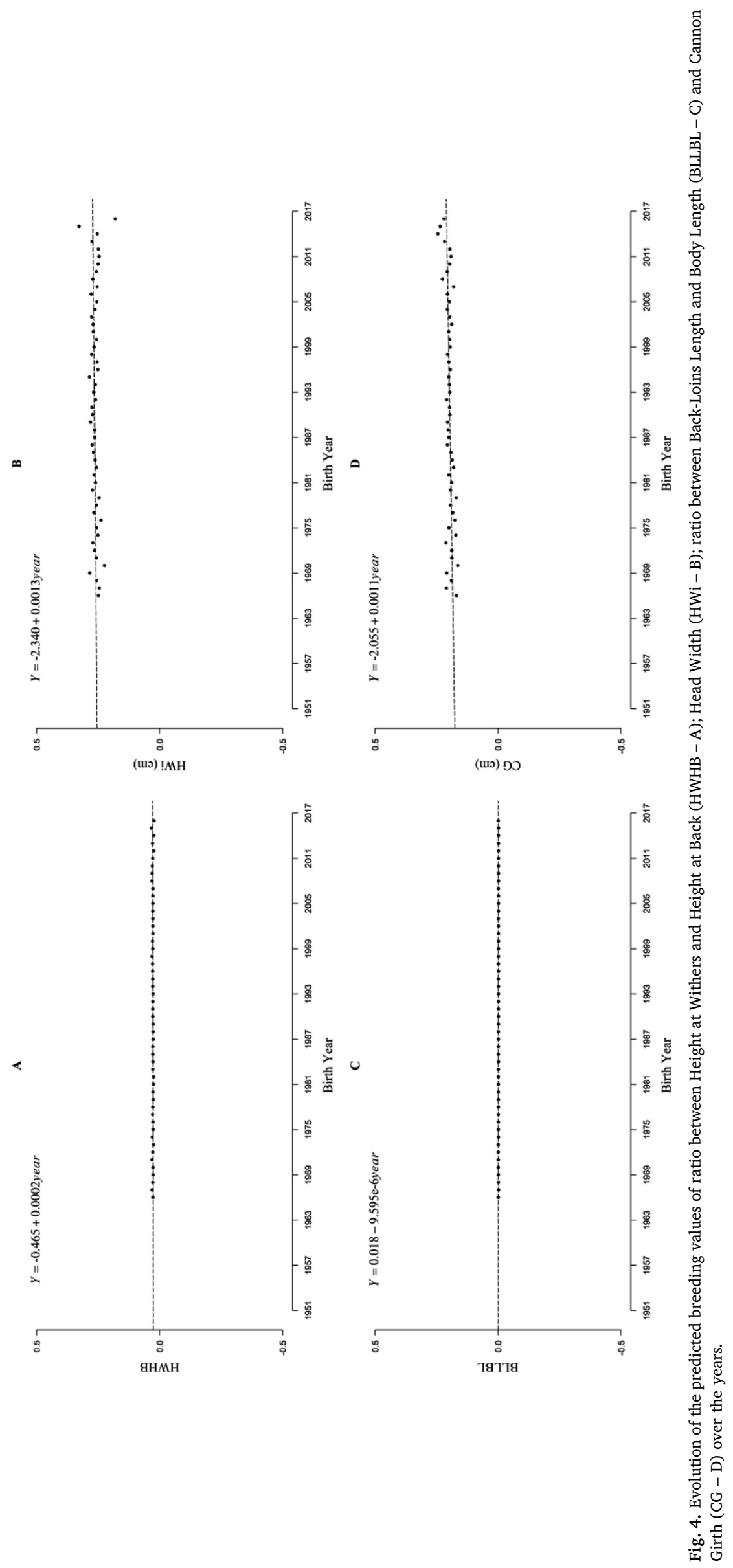
indicative of the convergence.

The infinitesimal model assumed to describe the traits is based on the normality of the genetic variance (Fisher, 1918). Once was adopted the infinitesimal model to explain the additive genetic variance, breeding values will follow a Gaussian distribution (Hayashi and Ukai, 1994). In this study the normality of the posterior distribution for all parameters and the breeding values was verified, corroborating for evidence of convergence of the chains. The only parameter which posterior distribution presented no Gaussian behavior was $\sigma_{T E C}^{2}$, but this could be related to the number of samples in the chain and the burn-in period (once the variance explained as proportion of the phenotypic variance was Gaussian), but also to the biased effect of the evaluator.

It is possible that multi-trait models could benefit predictions in younger animals, since the average accuracy was higher in mares than in stallions for the multi-trait model. Allied to the fact that the accuracy was the same (multi- or single-trait) for the stallions, not depending on the number of progenies, it is possible that the own phenotype in mares and younger animals without progeny has led to a greater accuracy, coming not only from the additive genetic variance to GtS, but also from genetic correlation with other traits. The average accuracy was also higher for the multi-trait model, which would indicate that this methodology is a good strategy if one wanted to select animals for GtS.

The results of additive genetic variance found in this study suggest that the Campolina population could be selected for morphology, and due to the large numbers of traits, the process of selection could be performed by elaborating indexes such as suggest by Vicente et al. (2014a). Ducro et al. (2007) and Holmström et al. (1990) suggest a twostep approach for selection in horses, in which the animals are first culled based on their morphology and after by the performance in equestrian events. It has been partially conducted by the ABCCCampolina wherein only animals that have their morphological features in accordance with the genealogical registration regulation (which guarantees the morphology guidelines for the breed) are registered and certified. In addition to that, the animals that have good results in the competitions of this breed are most likely the ones who will have more progeny.

Molina et al. (1999) reported heritability coefficients estimates of 0.58 and 0.49 , respectively for HW and HCh and a genetic correlation with BL of 0.55 and 0.47 (HW and HCh, respectively) in the Andalusian horse. In the present study were estimated heritabilities of 0.43 and 0.19 for the same traits, which could be related to the recent and diverse origin (many horse breeds in composition) of this breed and the absence of genetic selection until the present moment, once the Campolina is a young breed under phenotypic selection, alleles for most traits and the biological type were not yet fixed in the population. The greater correlation with BL found in this study $(0.818$ and 0.673 , for HW and HCh with BL, respectively), may be related with the proportions of the Campolina, which is a saddle horse but still reminding a draught horse due the compact body and position of shoulders.

The estimated heritability for NL in this study $(0.20)$ was near to the result obtained by Rustin et al. (2009) in the Belgian warmblood horse (0.27). For SL and CL, the values found here were lower than reported by the same authors ( 0.16 and $0.31,0.15$ and 0.30 , respectively). This similarity in the magnitude of genetic variance for those traits could, again, occur due to the origins of the Campolina breed, which was based on use of European stallions in crossbred Iberian mares. The heritability estimated in this study for CL was close to found by Vostry et al. (2017), in the Czech draught horse (0.14), which reinforce the genetic similarity of Campolina with the draught horses in the croup and shoulder lengths.

In the Lusitano horse, Vicente et al. (2014a) found the same pattern of genetic correlations between morphological traits (positive and ranging from moderate do high coefficients). Results obtained in the present study support the idea that the proportions of the horse body follow a pattern of lengths, widths and heights. In the case of the genetic correlation between BLLBL and HCh $(-0.091)$, despite negative, it is favorable to selection, as animals with longer HCh and lower relationship BLL/BL are desired by the Campolina horse breeders. The genetic correlation between BLLBL and LL (0.069) was also favorable, on this account as greater the leg (in length), lower will be this ratio. Horses with adequate length of legs and reduced length of BLL, in general, will have good scores in the gaits competitions and are well valued by breeders. The HWHB trait was positively correlated with BLLBL, showing that animals with good harmony in heights also have good harmony in lengths. Once the ratio between HW and HB should not increase, as desired by the ABCCCampolina, the genetic correlation between HWHB and HCh $(-0.444)$ show that animals with greater HCh bring more stable HW/HB ratio.

In this study, GtS was negatively correlated with all the morphological traits, showing that the breeder's goal for an animal that have both adequate morphology and gaits may not be easily achieved. Molina et al. (1999) found positive genetic correlations between functional and morphological traits in the Andalusian horse; that was also reported by Vicente et al. (2014a) in the Lusitano horse. In the present study, the large effect of technician over GtS may also have influenced in the directionality of genetic correlations. Thus, strategies (such as frequent training) must be created to reduce the magnitude of this effect in order to improve genetic predictions for gaits in the Campolina breed.

Rustin et al. (2009) found negative genetic correlations between functional traits and scores of conformation of head and neck in the Belgian Warmblood horse, and Vostry et al. (2017) also found negative genetic association between gaits and some morphological traits in the Czech Draught horse. This corroborate with the results found in the present study, once the patterns of correlations between functional and conformation traits on Campolina horses seems to be more like that showed on draught horses, despite the Iberian origins of this breed; due the large use of draught animals on the formation of the Campolina breed, it is plausible to observe the same patterns of genetic associations between those phenotypes.

The low heritability found for GtS in this study was probably associated to the technician effects. Velie et al. (2015) have reported the effects of riders and environment reducing the genetic variance for functional traits in the Australian Thoroughbred horse. In this case, random effects of the trainer ranged from $0.57 \%$ to $32.41 \%$ from the total phenotypic variation. In the present study the random effect of technician represented $60 \%$ of the total phenotypic variance. Score traits are sometimes preferred over direct measures for its price and time/logistics to record (Rustin et al., 2009; Vicente et al., 2014a, 2014b), however, it depends largely on the subjectivism which is natural to all situations where different people need to evaluate a specific feature. In this case, an effective training gets very important, in order to achieve homogeneous criteria among the different technicians responsible for scoring the animals and/or kinematic techniques to reduce subjectivity on gaits scoring. The large effect estimated for the technician variance component may be related to an inefficient training process, causing a heterogeneity between scores given by different technicians. Also, the scores are designated by the technician inside each type of gaits, which mean that the scores are given based on previous concepts of each gaits type.

The number of animals with phenotypes for GtS was significantly smaller than for the morphological traits, which may have negatively impacted the Markov-Chain process, and consequently the estimated parameters. The $\mathrm{CH}$ traits are both positively related to gaits, which means that the gaits were not genetically associated with any particular morphological trait (on the contrary, it is negatively related), but with proportions between morphological measurements. The genetic association between functional and conformation traits in horses have been described by Sánchez et al. (2013). These authors found that kinematic traits are, in general, positively correlated with morphology, showing that more objective traits to measure gaits have the capability to take benefit of morphological selection (positive correlations implying in an 
increase of both traits). Those results, in conjunction with the extremely large effect of technician, reinforce the need to find new phenotypes or methodologies to measure gaits in the Campolina horse. Kinematic traits could be a solution for that, as they are more accurate and eliminate the subjective effects inherent of the score traits (Molina et al., 2008; Solé et al., 2014).

Genetic correlations, which included zero (0) in the HPDinterval, were considered not significant in the present study, however, values obtained for those parameters indicate that selection for $\mathrm{CH}$ traits would not impact the actual morphology of the Campolina horse and could benefit selection for gaits. Future inclusion of new phenotypic data could improve the estimation of a HPDinterval for the genetic correlations between GtS, BLLBL and HWHB. Hilla \& Distl (2014) showed that body conformation could be associated with health of the limbs. This result suggests the importance of studying morphological traits. Since the purpose of the Campolina is the well-balanced gaits, it would be of value to focus on a good status and health of limbs for future individuals.

Due the adjustment of the genetic basis for the year 1951, all breeding values were expressed as a deviation from the genetic base, defined as the ABCCCampolina foundation. In this case the linear coefficient of the estimated trend represents how breeding values increased from the basis in each year. The results found in this study were in accordance to those reported by Bramante et al. (2016) in the Murgese horse and Vicente et al. (2014b) in the Lusitano horse. These authors also found low coefficients for the linear increase on the breeding values in each observed year. Nevertheless, the increase in the genetic breeding value $(137.9 \%)$ for each trait was significant $(P<0.001)$ and the phenotypic means for each trait showed also an increase $(100 \%)$ in the studied period.

It was expected that the estimated trends for GtS should be close to zero as it was never included as an actual selection criterion in this population. These results corroborate the need of new phenotyping strategies and new methodologies in order to adequately assess the genetic merit of Campolina animals for gaits.

\section{Conclusions}

Results reported in the present study suggest the existence of sufficient additive genetic variance underlying the investigated traits, indicating the possibility of implementation of a selection program. Morphological traits were negatively associated to the gaits total score trait, which in addition to the large effects of technician estimated, support the development of new phenotyping strategies for gaits. Correlations between gaits and morphological traits/conformation harmony suggest that gaits are not associated with body measurements but with the overall horse body proportion. Despite the absence of an efficient breeding program, favorable genetic trends were observed for the Campolina breed in this investigation.

\section{Acknowledgments}

The authors would like to thank the Brazilian Association of the Horse Breeders Campolina, that provided its database, and the Group of Genetic Improvement and Biotechnology from University of São Paulo (GMAB-FZEA/USP) for all support on analyses.

\section{Conflict of interest statement}

The authors declare that there are no conflicts of interest to this publication.

\section{Supplementary materials}

Supplementary material associated with this article can be found, in the online version, at doi:10.1016/j.livsci.2018.08.002.

\section{References}

Bates, D., Mächler, M., Bolker, B., Walker, S., 2014. Fitting linear mixed-effects models using lme4. J. Stat. Softw. 67. https://doi.org/10.18637/jss.v067.i01.

Bramante, G., Cito, A.M., Ciani, E., Pieragostini, E., 2016. Multi-trait animal model estimation of genetic parameters for morphometric measurements in the Murgese horse breed. Livest. Sci. 191, 139-142. https://doi.org/10.1016/j.livsci.2016.07.011.

Bussiman, F.O., Perez, B.C., Ventura, R.V., Peixoto, M.G.C.D., Curi, R.A., Balieiro, J.C.C., 2018. Pedigree analysis and inbreeding effects over morphological traits in Campolina horse population. Animal 1-10. https://doi.org/10.1017/ S175173111800023X.

Cowles, M.K., Carlin, B.P., 1996. Markov Chain Monte Carlo Convergence diagnostics: a comparative review. J. Am. Stat. Assoc. 91, 883-904. https://doi.org/10.1080/ 01621459.1996.10476956.

Ducro, B.J., Koenen, E.P.C., van Tartwijk, J.M.F.M., Bovenhuis, H., 2007. Genetic relations of movement and free-jumping traits with dressage and show-jumping performance in competition of Dutch Warmblood horses. Livest. Sci. 107, 227-234. https:// doi.org/10.1016/j.livsci.2006.09.018.

Fisher, R.A., 1918. The correlation between relatives on the supposittion of mendelian inheritance. Trans. R. Soc. Edinb. Earth Sci. 52, 399-433.

Geweke, J., 1992. Evaluating the accuracy of sampling-based approaches to the calculation of posterior moments. Bayesian Stat. 4, 169-193. https://doi.org/1176289.

Hayashi, T., Ukai, Y., 1994. Change in genetic variance under selection in a self-fertilizing population. Genetics 136, 693-704.

Heidelberger, P., Welch, P.D., 1983. Simulation run length control in the presence of an initial transient. Oper. Res. 31, 1109-1144. https://doi.org/10.1287/opre.31.6.1109.

Henderson, C.R., 1975. Best linear unbiased estimation and prediction under a selection model. Biometrics 31, 423-447.

Hilla, D., Distl, O., 2014. Heritabilities and genetic correlations between fetlock, hock and stifle osteochondrosis and fetlock osteochondral fragments in Hanoverian Warmblood horses. J. Anim. Breed. Genet. 131, 71-81. https://doi.org/10.1111/jbg. 12062.

HolmstrÖM, M., MAGNUSSON, L.-E, PHILIPSSON, J., 1990. Variation in conformation of Swedish Warmblood horses and conformational characteristics of élite sport horses. Equine Vet. J. 22, 186-193. https://doi.org/10.1111/j.2042-3306.1990.tb04245.x.

Lassen, J., Sørensen, M.K., Madsen, P., Ducrocq, V., 2007. An approximate multitrait model for genetic evaluation in dairy cattle with a robust estimation of genetic trends. Genet. Sel. Evol. 39, 353-367. https://doi.org/10.1051/gse:2007008.

Misztal, I., Tsuruta, S., Strabel, T., Auvray, B., Druet, T., Lee, D.H., 2002. BLUPF90 and related programs (BGF90). In: Proceedings of the Seventh World Congress on Genetics Applied to Livestock Production, pp. 21-22. https://doi.org/ 9782738010520.

Molina, A., Valera, M., Dos Santos, R., Rodero, A., 1999. Genetic parameters of morphofunctional traits in Andalusian horse. Livest. Prod. Sci. 60, 295-303. https://doi org/10.1016/S0301-6226(99)00101-3.

Molina, A., Valera, M., Galisteo, A.M., Vivo, J., Gómez, M.D., Rodero, A., Agüera, E., 2008. Genetic parameters of biokinematic variables at walk in the Spanish Purebred (Andalusian) horse using experimental treadmill records. Livest. Sci. 116, 137-145. https://doi.org/10.1016/j.livsci.2007.09.021.

Plummer, M., Best, N., Cowles, K., Vines, K., 2006. CODA: convergence diagnosis and output analysis for MCMC. R News 6, 7-11. https://doi.org/10.1159/000323281.

Procópio, A.M., Bergmann, J.A.G., Costa, M.D., 2003. Formação e demografia da raça Campolina. Arq. Bras. Med. Vet. e Zootec. 55, 361-365. https://doi.org/10.1590/ S0102-09352003000300018.

R Core Team, 2016. R development core team. R A Lang. Environ. Stat. Comput. https:// doi.org/http://www.R-project.org.

Raftery, A.E., Lewis, S., 1992. How many iterations in the Gibbs sampler? Bayesian Stat. $763-773$.

Rezende, A.S.C., Moura, R.S., 2004. Raças De Equídeos No Brasil. Federal University of Minas Gerais, Belo Horizonte.

Rustin, M., Janssens, S., Buys, N., Gengler, N., 2009. Multi-trait animal model estimation of genetic parameters for linear type and gait traits in the Belgian warmblood horse. J. Anim. Breed. Genet. 126, 378-386. https://doi.org/10.1111/j.1439-0388.2008. 00798.x.

Sánchez, M.J., Gómez, M.D., Peña, F., García, J.M., Morales, J.L., Molina, A., Valera, M., 2013. Relationship between conformation traits and gait characteristics in Pura Raza Español horses. Arch. Tierzucht 56, 137-148. https://doi.org/10.7482/0003-943856-013.

Solé, M., Santos, R., Molina, A., Galisteo, A., Valera, M., 2014. Genetic analysis of kinematic traits at the trot in Lusitano horse subpopulations with different types of training. Animal 8, 192-199. https://doi.org/10.1017/S1751731113002036.

Sorensen, D., Gianola, D., 2002. Likelihood, Bayesian and MCMC Methods in Quantitative Genetics. Springer-Verlag, New York.

Thompson, R., Meyer, K., 1986. A review of theoretical aspects in the estimation of breeding values for multi-trait selection. Livest. Prod. Sci. 15, 299-313. https://doi. org/10.1016/0301-6226(86)90071-0.

van der Werf, J.H.J., van Arendonk, J.A.M., De Vries, A.G., 1992. Improving selection of pigs using correlated characters. In: Proceedings of the 43th EAAP Annual Meeting Book of Abstracts of European Federation of Animal Science. Madrid.

Velie, B.D., Hamilton, N.A., Wade, C.M., 2015. Heritability of racing performance in the Australian Thoroughbred racing population. Anim. Genet. 46, 23-29. https://doi. org/10.1111/age.12234.

Vicente, A.A., Carolino, N., Ralão-Duarte, J., Gama, L.T., 2014a. Selection for morphology, gaits and functional traits in Lusitano horses: I. Genetic parameter estimates. Livest. Sci. 164, 1-12. https://doi.org/10.1016/j.livsci.2014.01.020. 
Vicente, A.A., Carolino, N., Ralão-Duarte, J., Gama, L.T., 2014b. Selection for morphology, gaits and functional traits in Lusitano horses: II. Fixed effects, genetic trends and selection in retrospect. Livest. Sci. 164, 13-25. https://doi.org/10.1016/j.livsci. 2014.03.017.

Vieira, E.R., de Rezende, A.S.C., Lana, Â.M.Q., Barcelos, K.M.C., Santiago, J.M., Lage, J., Fonseca, M.G., Bergmann, J.A.G., 2015. Caracterização da equideocultura no estado de Minas Gerais. Arq. Bras. Med. Vet. e Zootec. 67, 319-323. https://doi.org/10. 1590/1678-7460.
Villanueva, B., Wray, N.R., Thompson, R., 1993. Prediction of asymptotic rates of response from selection on multiple traits using univariate and multivariate best linear unbiased predictors. Anim. Sci. 57, 1-13. https://doi.org/10.1017/ S0003356100006541.

Vostry, L., Vostrà-vydrovà, H., Hofmanovà, B., Veselà, Z., Schmidovà, J., Majzlik, I., 2017. Genetic parameters for linear type traits in th ree Czech draught horse breeds. Agric. Conspec. Sci. 82, 111-115. 